\title{
POSSIBLE EFFECTS OF OZONE DEPLETION ON THE GLOBAL CARBON CYCLE
}

\author{
TSUNG-HUNG PENG
} Environmental Sciences Division, Oak Ridge National Laboratory, Oak Ridge, Tennessee 37831
USA

\begin{abstract}
The increase of UV-B radiation resulting from ozone depletion is considered to have damaging effects on marine ecosystems. A cutback of marine productivity would tend to reduce the oceanic uptake of atmospheric $\mathrm{CO}_{2}$. Box models of the global oceans based on the distribution of bomb-produced ${ }^{14} \mathrm{C}$ are used to evaluate the possible effects of ozone depletion on the atmospheric $\mathrm{CO}_{2}$ concentration. The maximum effect presumably takes place if the ozone hole reduces the marine productivity to zero in the Antarctic Ocean. In a business-as-usual scenario of future $\mathrm{CO}_{2}$ emissions, the atmospheric $\mathrm{CO}_{2}$ partial pressure $\left(\mathrm{pCO}_{2}\right)$ would increase by an additional $37 \mu$ atm over the course of the next century. This increase corresponds to $4.6 \%$ of the projected atmospheric $\mathrm{pCO}_{2}$ in the year 2090 . However, if the damaging effect caused by the destruction of the stratospheric ozone layer is assumed to lower the productivity over the Antarctic Ocean by $10 \%$, the atmospheric $\mathrm{pCO}_{2}$ would rise by less than $3 \mu \mathrm{atm}$ over the expected atmospheric level in the next century.
\end{abstract}

\section{INTRODUCTION}

The ozone layer in the stratosphere serves as a shield protecting the Earth's surface from solar ultraviolet radiation. Heath (1988) reported changes in total column ozone from 1970 to 1986, based on satellite observations. For example, the stratospheric ozone between $65^{\circ} \mathrm{N}$ and $65^{\circ} \mathrm{S}$ decreased about 5\% between 1978 and 1986. Farman, Gardiner and Shanklin (1985) observed large losses of total ozone in Antarctica during the austral spring (ozone hole, a loss of total ozone reached 50\% within the hole in October 1987), and linked them with the increase in concentrations of chlorofluorocarbons (CFCs) in the atmosphere. These chemicals are released into the atmosphere through their use in foam production, refrigerants, aerosol sprays and halons in fire extinguishers. The inorganic chlorine derived from these human pollutants photochemically catalyzes the reaction that changes ozone into oxygen, and leads to destruction of ozone in the stratosphere.

The 31-nation Montreal Protocol calls for a 50\% reduction from 1986 production levels by 1998 and predicted that, if these nations adhere to the Protocol, the ozone loss at most latitudes would be only a few percentage points. However, the discovery of the Antarctic ozone hole and its significance regarding the enhanced potency of CFCs and stratospheric ice particles to ozone destruction lead to the realization that the Protocol's proposed CFC control measures may not be sufficient. In response, the Protocol was revised recently to phase out CFC production by the year 2000. Ozone scientists who study the problem fear that even this measure may not be enough to hold ozone depletion to tolerable levels (Kerr 1991). Further, the residence time of CFCs in the atmosphere is on the order of a few hundred years, so the destruction of ozone in the stratosphere is expected to continue in the next century, even if control policies to curb the further release of CFCs into the atmosphere are successfully implemented. Hardy and Gucinski (1989) predicted that the total decline from 1969 to 2060 might reach more than $16 \%$ in the southern latitudes and at least $14 \%$ at northern latitudes in the winter.

The direct consequence of a decreasing ozone layer is the increase in ultraviolet radiation reaching the Earth's surface. In general, shorter wave lengths of ultraviolet radiation are more damaging to biological processes than longer wave lengths (Jagger 1985). The short wave length UV-B radiation $(280-320 \mathrm{~nm})$ thus becomes the focus for estimating effects of ozone depletion on marine ecosystems. Much research has focused on the effects of increasing UV-B radiation on phytoplankton (Worrest 1986; Smith \& Baker 1989), zooplankton, benthos and fish (Hardy \& Gucinski 1989). Although some degree of damage is expected, these estimates contain considerable uncertainty. It 
is not possible, for example, to relate a quantitative reduction of primary productivity to a given extra dose of UV-B radiation. Worrest (1986) concludes that an enhanced UV-B exposure is more likely to change species composition of the marine plant communities than to decrease the net production. In the case of UV-B effects on fish, however, Worrest (1986) reports that about a 9\% decrease in the atmospheric ozone column would induce a $20 \%$ increase in biologically damaging UV-B radiation, which would kill about $8 \%$ of the annual anchovy larval population throughout the water column.

Because of the expected damage to primary productivity in the ocean under a continuing depletion of ozone layer, concerns about indirect effects of ozone depletion on the global carbon cycle have been suggested (H. Lee II, personal communication 1991). The reduced marine productivity would weaken the biological $\mathrm{CO}_{2}$ pump, and hence, would cause atmospheric $\mathrm{CO}_{2}$ to rise above the expected level. Such an increase in atmospheric $\mathrm{CO}_{2}$ would further enhance the probability of climate change induced by Greenhouse warming. For this reason, we need to examine the sensitivity of oceanic $\mathrm{CO}_{2}$ uptake to possible reductions in biological productivity caused by the increasing UV-B radiation resulting from stratospheric ozone depletion. Although a quantitative effect of ozone depletion on primary productivity in the ocean is not available, limits of the possible effects on the atmospheric $\mathrm{CO}_{2}$ level could be estimated using box models of the ocean, properly calibrated with the distribution of ${ }^{14} \mathrm{C}$ in the ocean. I estimate here these possible effects of ozone depletion on atmospheric $\mathrm{CO}_{2}$.

\section{OCEAN MODEL BASED ON RADIOCARBON DISTRIBUTION}

Marine biological activity plays an important role in the global carbon cycle. Today, oceanic plants growing in temperate and tropical regions use nutrients (e.g., phosphate and nitrate) so efficiently that the partial pressure of $\mathrm{CO}_{2}\left(\mathrm{pCO}_{2}\right)$ in surface water is reduced to the minimum. This is because the plant growth reduces the total $\mathrm{CO}_{2}$ content of the surface water. By contrast, oceanic nutrients are not efficiently used in the polar regions. Martin, Fitzwater and Gordon (1990) and Martin, Gordon and Fitzwater (1990) proposed to add iron to these regions, which would enhance the biological productivity, and thus, would take up extra $\mathrm{CO}_{2}$ from the atmosphere. Peng and Broecker (1991a) devised a box model of the ocean to test how effectively the iron fertilization in the Antarctic Ocean would lower the atmospheric $\mathrm{pCO}_{2}$ in the next century. In this case, the biological productivity is enhanced to take up more $\mathrm{CO}_{2}$ for the purpose of reducing the potential of Greenhouse warming. The ozone depletion, however, would have the opposite effect on biological productivity and cause the atmospheric $\mathrm{CO}_{2}$ to rise. The ozone hole discovered in Antarctica presents a greater possibility for damaging phytoplankton in the Antarctic Ocean than in the other parts of the global oceans. Thus, we can use the same ocean model developed by Peng and Broecker (1991a) to simulate the effects of the damaged marine ecosystems in the Antarctic Ocean on raising the atmospheric $\mathrm{CO}_{2}$ level in the next century.

Peng and Broecker (1991a) described the model in detail. Figure 1 shows a brief summary of the model. The world ocean is represented by five boxes: surface mixed layers of Antarctic and nonAntarctic (0-75 m), diffusive layers of Antarctic and non-Antarctic (75-2000 m) and a well-mixed deep sea (2000-4000 m). A well-mixed atmosphere over the ocean surface mixed layer is added to complete a closed ocean-atmosphere carbon system. The exchange rate of $\mathrm{CO}_{2}$ across the sea-air interface is taken to be $20 \mathrm{~mol} \mathrm{~m}^{-2} \mathrm{yr}^{-1}$ for a $\mathrm{pCO}_{2}$ of $330 \mu \mathrm{atm}$ (Peng et al. 1979). The sea surface area over the Antarctic Ocean is assumed to be $10 \%$ of the global ocean surface area. The remaining $90 \%$ surface area is assigned to non-Antarctic oceans. Based on measurements made during the Geochemical Ocean Sections Study (GEOSECS) program, the inventory of bomb-produced ${ }^{14} \mathrm{C}$ in the Antarctic Ocean shows a consistent deficiency compared with the amount expected 


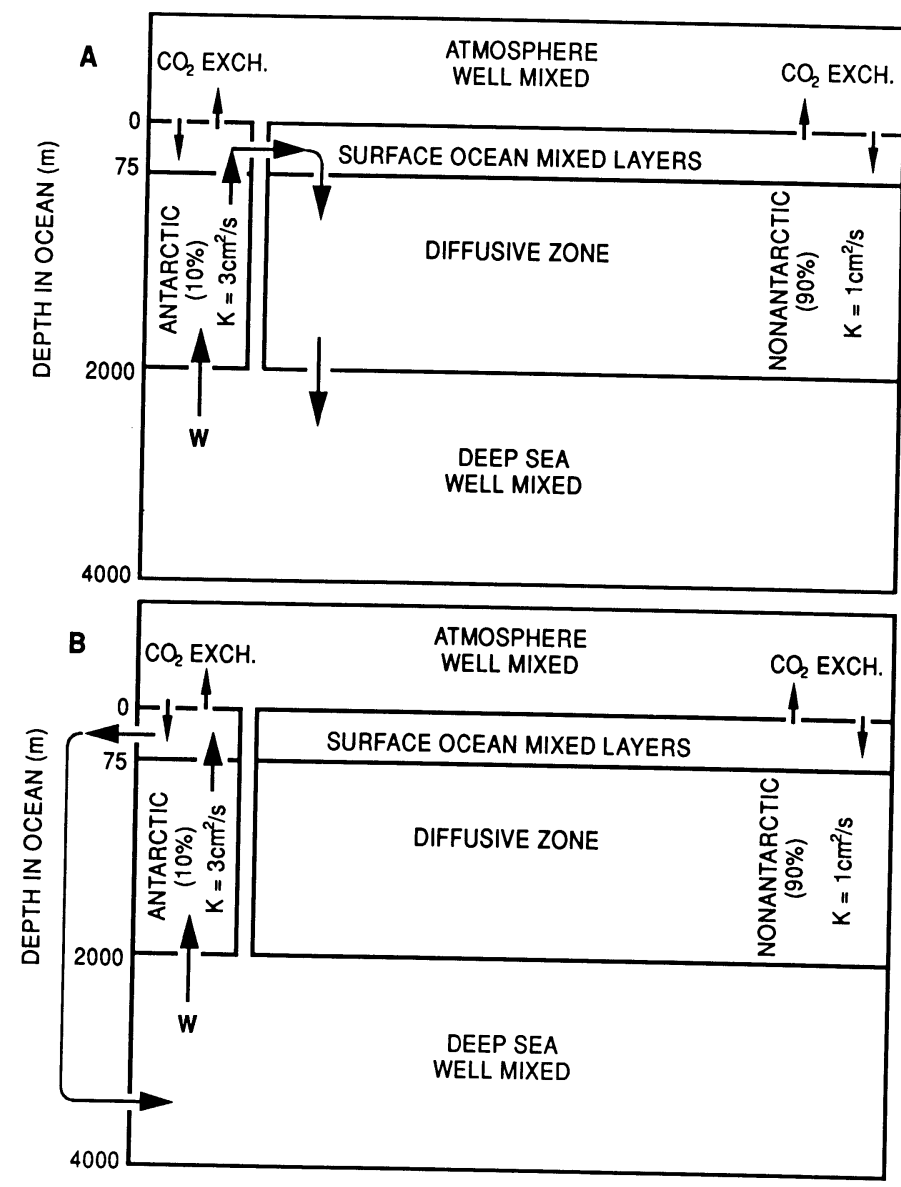

Fig. 1. Linked vertical advection-diffusion model used to evaluate the response to increased UV-B radiation over Antarctic surface waters. The upwelling and vertical eddy diffusion parameters are derived from the distribution of bomb-produced ${ }^{14} \mathrm{C}$ obtained during the GEOSECS program. A shows the lateral transfer of water upwelled in the Antarctic to the nonAntarctic surface ocean. B shows this upwelled water converted to deep water and transferred directly to the model's deep reservoir. The upper $2000 \mathrm{~m}$ of the ocean column is essentially the box-diffusion model of Oeschger et al. (1975).

if ${ }^{14} \mathrm{C}$ enters the ocean through the gas exchange process (Broecker et al. 1985). This deficiency traditionally implies that deep ocean water upwells in this region. A portion of this upwelled water moves beneath the sea-ice fringe, where its density increases by brine release, causing it to sink back into the deep sea. The remainder moves to the north. Some becomes intermediate water, which penetrates northward into the Atlantic, Pacific and Indian Oceans, and some is mixed into the temperate surface water. Because little is known about what portion of upwelled water forms deep water, and what portion forms temperate surface and intermediate water, two separate models represent both cases. One, the lateral transport model, depicts the lateral transport of the upwelled water to form temperate surface and intermediate water (Fig. 1A). The other, the deep transport model, depicts the deep transport of the upwelled water to form deep water (Fig. 1B). The real world should lie between these two extreme cases.

The upwelling rate required to generate the observed ${ }^{14} \mathrm{C}$ deficiency in the Antarctic Ocean is $15 \mathrm{~m} \mathrm{yr}^{-1}$ (Broecker et al. 1985). Because the Antarctic surface area is taken to be $10 \%$ of the total ocean area, this upwelling rate corresponds to a water flux of $17.4 \mathrm{~Sv}\left(17.4 \times 10^{6} \mathrm{~m}^{3} \mathrm{~s}^{-1}\right)$. The 
mean penetration depth of bomb-produced ${ }^{14} \mathrm{C}$ for 15 GEOSECS profiles for latitudes south of $49^{\circ}$ $\mathrm{S}$ is $260 \mathrm{~m}$ (Broecker et al. 1985). This extent of penetration into the upwelling plume can be obtained by using a vertical eddy diffusivity of $3 \mathrm{~cm}^{2} \mathrm{~s}^{-1}$. These values are adopted in the model parameters for the Antarctic boxes. In addition, we set the vertical eddy diffusivity in the non-Antarctic region at $1 \mathrm{~cm}^{2} \mathrm{~s}^{-1}$, which also derives from the GEOSECS bomb- ${ }^{14} \mathrm{C}$ distribution.

The biological productivity in the surface mixed layer depends on the availability of nutrients, which are, in general, represented by the $\mathrm{PO}_{4}$ content in seawater. A strong biological productivity quickly reduces $\mathrm{PO}_{4}$ content in the surface mixed layer. Thus, the biological removal of carbon and nutrients from the surface euphotic layer can be simulated by the residence times of $\mathrm{PO}_{4}$ in the mixed layer and the Redfield C:P ratio. The simulation starts with steady-state distribution of $\mathrm{PO}_{4}$ in the ocean with residence time of 3.5 years in the Antarctic to yield $1.6 \mu \mathrm{mol} \mathrm{kg}^{-1}$ of $\mathrm{PO}_{4}$ in the surface water over the Antarctic column, and with residence time of 0.5 years in the non-Antarctic region to yield near zero $\mathrm{PO}_{4}$ over the non-Antarctic column. The remineralization function for sinking organic matter was set to yield $\mathrm{PO}_{4}$ profiles similar to those observed. The Redfield ratio of carbon atom to phosphorus atom in the falling organic debris is 130. A steady-state global carbon cycle is then calculated by adjusting the total $\mathrm{CO}_{2}$ and alkalinity in the model ocean to yield a preindustrial atmospheric $\mathrm{pCO}_{2}$ of $280 \mu \mathrm{atm}$.

In order to evaluate the possible effects of increasing UV-B radiation resulting from continuous depletion of the stratospheric ozone layer in the next century on increasing atmospheric $\mathrm{pCO}_{2}$ level caused by uncontrolled release of anthropogenic $\mathrm{CO}_{2}$, we need to know the relationship between UV-B radiation increase and marine productivity reduction. Because a quantitative destruction of marine productivity by excess UV-B radiation is not known, we assume a hypothetical case of maximum effect in which the plant productivity in the Antarctic Ocean is completely eliminated by a persistent ozone hole for the next century. However, the destruction over the non-Antarctic region is assumed negligible because of less serious ozone depletion. The elimination of marine productivity in the Antarctic Ocean is simulated by setting an infinite $\mathrm{PO}_{4}$ residence time in the surface water of this region.

The fossil-fuel $\mathrm{CO}_{2}$ emission (Fig. 2) for the next century (1990-2090) is taken from an Intergovernmental Panel on Climate Change (IPCC) business-as-usual scenario (Houghton, Jenkins \& Ephraums 1990). The input of man-made $\mathrm{CO}_{2}$ into the atmosphere started in 1800 and continued through 1990. During that period, the fossil-fuel production is based on Marland's (1990) estimates. The release of $\mathrm{CO}_{2}$ from the terrestrial ecosystem is obtained by deconvolution (Peng 1991) of time history of atmospheric $\mathrm{pCO}_{2}$ based on $\mathrm{pCO}_{2}$ measurements of air bubbles in ice cores (Neftel et al. 1985) and of air samples (Keeling et al. 1989). The amount of terrestrial $\mathrm{CO}_{2}$ release after 1990 is assumed to remain constant at the 1990 level.

\section{RESULTS AND DISCUSSIONS}

The effect of the ozone hole on Antarctic productivity was assumed to start in 1991 after a steady-state global carbon cycle was perturbed with man-made $\mathrm{CO}_{2}$ beginning in 1800 . The elimination of marine productivity in the Antarctic Ocean releases oceanic $\mathrm{CO}_{2}$ back to the atmosphere. As a result, the atmospheric $\mathrm{pCO}_{2}$ elevates above the level expected if the ozone hole does not disturb the marine biological activity. The increase in atmospheric $\mathrm{pCO}_{2}\left(\Delta \mathrm{pCO}_{2}\right)$ is defined as the difference in atmospheric $\mathrm{pCO}_{2}$ with and without ozone effects. As shown in Figure $3 \mathrm{~A}$ for the deep transport model, the $\Delta \mathrm{pCO}_{2}$ increases with time and reaches $37 \mu \mathrm{atm}$ by the year 2090 , which is about $4.6 \%$ of the projected $\mathrm{pCO}_{2}$ level (i.e., $\sim 800 \mu \mathrm{atm}$ ) at that time in a normal atmosphere with no ozone hole. The percentage of $\Delta \mathrm{pCO}_{2}$ changes only very sightly with time after 


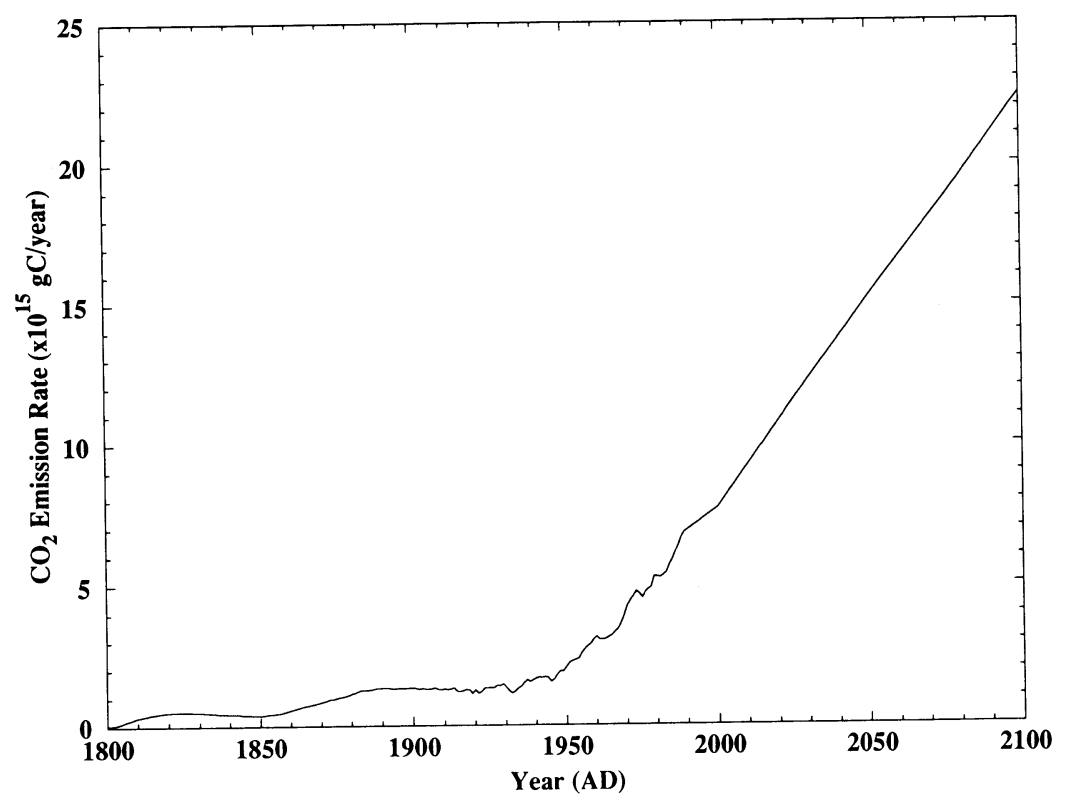

Fig. 2. Scenario of fossil fuel $\mathrm{CO}_{2}$ emissions based on an IPCC business-as-usual case for the next century. The time history of $\mathrm{CO}_{2}$ release between 1800 and 1990 is based on Marland's (1990) estimates for fossil-fuel production and deconvolution results (Peng 1991) for terrestrial $\mathrm{CO}_{2}$ release based on the atmospheric $\mathrm{CO}_{2}$ record.

50 years of ozone effects. The maximum ozone effect causes the $\mathrm{PO}_{4}$ concentration in the Antarctic surface water to change from 1.6 to $2.3 \mu \mathrm{mol} \mathrm{kg}{ }^{-1}$. For comparison, Figure 3 illustrates the decrease in atmospheric $\mathrm{pCO}_{2}$ if a completely successful iron fertilization in the Antarctic Ocean is implemented (Peng \& Broecker 1991b). The decrease caused by the iron-enhanced use of high nutrient concentration in the Antarctic surface water reaches $64 \mu \mathrm{atm}$ by the year 2090, which is about $8 \%$ of the expected normal atmospheric $\mathrm{pCO}_{2}$ at that time. The maximum iron fertilization effect causes the $\mathrm{PO}_{4}$ concentration in the Antarctic surface water to change, however, from 1.6 to near $0.0 \mu \mathrm{mol} \mathrm{kg}^{-1}$. These results, under the assumption of highly exaggerated effects on marine productivity, show that both the ozone hole and iron fertilization would not make a significant difference to the atmospheric $\mathrm{pCO}_{2}$ if fossil fuel $\mathrm{CO}_{2}$ emissions follow a business-as-usual scenario for the next century. However, results of box-model simulations for iron fertilization by Joos, Sarmiento and Siegenthaler (1991) and Joos, Siegenthaler and Sarmiento (1991) indicate that the reduction of atmospheric $\mathrm{pCO}_{2}$ could reach as high as $107 \mu \mathrm{atm}$. These authors expressed such reduction by the percentage of net increase in atmospheric $\mathrm{pCO}_{2}$ in the next 100 years. Thus, a $107-\mu$ atm reduction represents $24 \%$ of the predicted net increase in atmospheric $\mathrm{pCO}_{2}$ from 1991 to 2090 (i.e., $107 /(800-355) \times 100)$. Using a more sophisticated $3-\mathrm{D}$ ocean general circulation model, Sarmiento and Orr (1991) obtained a mean reduction of $72 \mu \mathrm{atm}$ in their iron fertilization simulations. Based on such a wide range of $\mathrm{pCO}_{2}$ reduction using various ocean models, we see that these model simulations contain a considerable amount of uncertainty.

In the case of the lateral transport model (Fig. 3B), the effects of both the ozone hole and iron fertilization on atmospheric $\mathrm{pCO}_{2}$ are smaller than those of the deep transport mechanism. For the ozone hole effect, atmospheric $\mathrm{pCO}_{2}$ increases $17 \mu \mathrm{atm}$ by the year 2090 . The iron fertilization, on the other hand, causes a $25 \mu \mathrm{atm}$ decrease in atmospheric $\mathrm{pCO}_{2}$. The main reason for a less effective influence on atmospheric $\mathrm{pCO}_{2}$ under the lateral transport mechanism is that the upwelled 


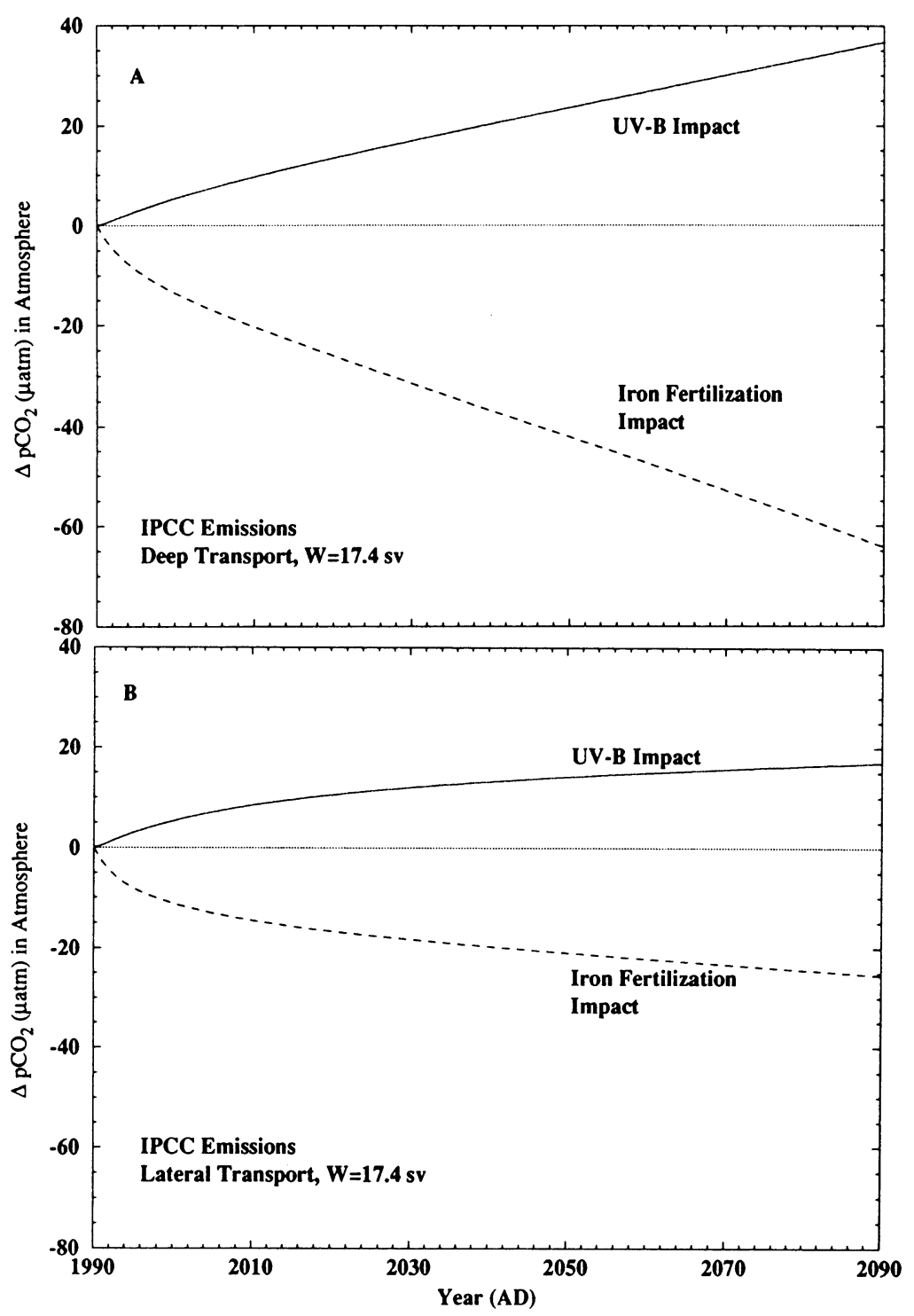

Fig. 3. Changes in atmospheric $\mathrm{pCO}_{2}$ resulting from ozone hole effect or iron fertilization in the Antarctic Ocean. $-=$ atmospheric $\Delta \mathrm{pCO}_{2}$ resulting from damages to marine production caused by the ozone hole. --- = atmospheric $\Delta \mathrm{pCO}_{2}$ resulting from enhanced marine production by iron fertilization. $\mathbf{A}$ is for deep transport; $\mathrm{B}$, lateral transport.

Antarctic water, after reaching the surface layer and being subjected to biological effects, is transported to the surface mixed layer of the non-Antarctic ocean, where $\mathrm{CO}_{2}$ is exposed to the atmosphere again and can exchange with atmospheric $\mathrm{CO}_{2}$. By contrast, the deep transport mode sends the Antarctic surface water into the deep ocean and effectively isolates $\mathrm{CO}_{2}$ from the atmosphere.

The Antarctic ozone hole is most apparent in the austral spring season. During the other seasons of the year, the ozone layer recovers mostly, and hence, offers some shielding function over the 
Antarctic Ocean. The model simulation of a year-round ozone hole effect of complete destruction over the Antarctic surface water is obviously inconsistent with current observations. Model simulations of ozone holes that are less destructive to marine ecosystems are made to show how atmospheric $\mathrm{pCO}_{2}$ would respond. Shown in Figure 4 are curves of increase in atmospheric $\mathrm{pCO}_{2}$ caused by $100 \%, 50 \%$ and $10 \%$ ozone hole effects using the deep-transport model. At $50 \%$ effective, the $\Delta \mathrm{pCO}_{2}$ in year 2090 drops from 37 to $15 \mu \mathrm{atm}$, and at $10 \%$ effective, it drops to less than $3 \mu \mathrm{atm}$. It is generally believed that the most likely overall damaging effect of ozone depletion would be below $10 \%$. If so, the model predicts a negligible effect on carbon cycle. Thus, the maximum effect of ozone depletion on atmospheric $\mathrm{pCO}_{2}$ in the next century would most likely be lower than $3 \mu \mathrm{atm}$.

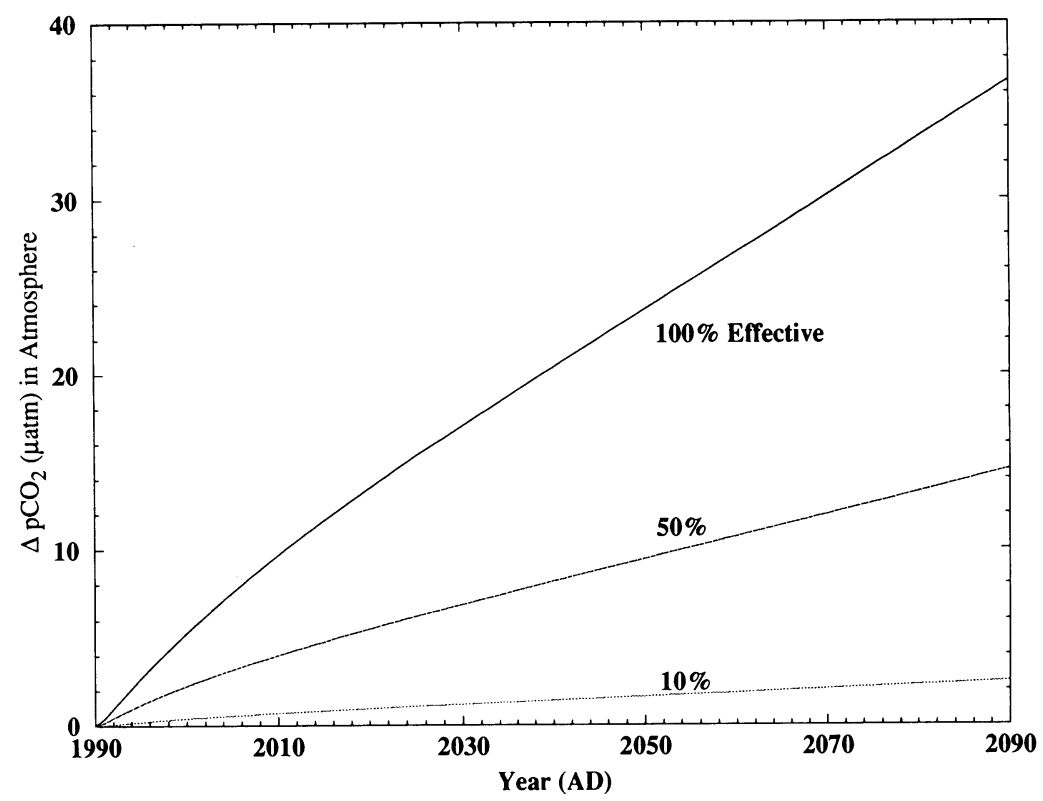

Fig. 4. Atmospheric $\mathrm{pCO}_{2}$ resulting from $100 \%, 50 \%$ and $10 \%$ effective damages to marine productivity caused by the Antarctic ozone hole. The deep-transport model and upwelling flux of $17.4 \mathrm{~Sv}$ are used.

\section{CONCLUSION}

The model simulations considering the real potential damaging effects of increased UV-B radiation on marine ecosystems reveal that the global carbon cycle would not be affected by ozone depletion in a significant way over the next century. A more detailed analysis would require a better understanding of the relationship between changes of UV-B radiation and phytoplankton productivity. In the present situation, the increase in atmospheric $\mathrm{pCO}_{2}$ would not be significantly enhanced by the stratospheric ozone depletion.

\section{ACKNOWLEDGMENT}

W. S. Broecker provided valuable suggestions in the model calculations and results presentation. J. L. Sarmiento gave a constructive review. Members of the Earth System Modeling Group of the Environmental Sciences Division helped with technical aspects of model simulations. Research sponsored by Carbon Dioxide Research Program, Environmental Sciences Division, Office of Health and Environmental Research, U.S. Department of Energy, under contract DE-AC05-84OR2- 
1400 with Martin Marietta Energy Systems, Inc., Publication No. 3819, Environmental Sciences Division, Oak Ridge National Laboratory.

\section{REFERENCES}

Broecker, W. S., Peng, T.-H., Ostlund, G. and Stuiver, M. 1985 The distribution of bomb radiocarbon in the ocean. Journal of Geophysical Research 90: 69536970.

Farman, J. C., Gardiner, B. G., and Shankin, J. D. 1985 Large losses of total ozone in Antarctica reveal seasonal $\mathrm{ClO}_{x} / \mathrm{NO}_{x}$ interaction. Nature 315: 207-210.

Hardy, J. and Gucinski, H. 1989 Stratospheric ozone depletion: Implications for marine ecosystems. Oceanography 2: 18-21.

Heath, D. F. 1988 Non-seasonal changes in total column ozone from satellite observations, 1970-86. Nature 332: 219-227.

Houghton, J. T., Jenkins, G. J. and Ephraums, J. J. 1990 Climate Change: The IPCC Scientific Assessment. Cambridge, Cambridge University Press: 329-341.

Jagger, J. 1985 Solar-UV Actions on Living Cells. New York, Praeger Publisher: $202 \mathrm{p}$.

Joos, F., Sarmiento, J. L. and Siegenthaler, U. 1991 Potential enhancement of oceanic $\mathrm{CO}_{2}$ uptake by iron fertilization of the Southern Ocean. Nature 349: 772-775.

Joos, F., Siegenthaler, U. and Sarmiento, J. L. 1991 Possible effects of iron fertilization in the Southern Ocean on atmospheric $\mathrm{CO}_{2}$ concentration. Global Biogeochemical Cycles 5: 135-150.

Keeling, C. D., Bacastow, R. B., Carter, A. F., Piper, S. C., Whorf, T. P., Heimann, M., Mook, W. G. and Roeloffzen, H. 1989 A three-dimensional model of atmospheric $\mathrm{CO}_{2}$ transport based on observed winds: 1. Analysis of observational data. Geophysical Monograph 55, American Geophysical Union: 165-231.

Kerr, R. A. 1991 Ozone destruction worsens. Science 252: 204.

Marland, G. 1990 Global $\mathrm{CO}_{2}$ emissions. In Boden, T. A., Kanciruk, P. and Farrell, M. P., eds., Trends '90: A Compendium of Data on Global Change. ORNL/ CDIAC-36: $92 \mathrm{p}$.

Martin, J. H., Fitzwater, S. E. and Gordon, R. M. 1990 Iron deficiency limits phytoplankton growth in Antarctic waters. Global Biogeochemical Cycle 4: 5-12.
Martin, J. H., Gordon, R. M. and Fitzwater, S. E. 1990 Iron in Antarctic waters. Nature 345: 156-158.

Neftel, A., Moor, E., Oeschger, H. and Stauffer, B. 1985 Evidence from polar ice cores for the increase in atmospheric $\mathrm{CO}_{2}$ in the past two centuries. Nature 315: 45-47.

Oeschger, H., Siegenthaler, U., Schotterer, U. and Gugelman, A. 1975 A box diffusion model to study the carbon dioxide exchange in nature. Tellus 27: 168-192.

Peng, T.-H. 1991 Oceanic $\mathrm{CO}_{2}$ uptake and future atmospheric $\mathrm{CO}_{2}$ concentrations. In Wilhelms, S. C. and Gulliver, J. S., eds., Air-Water Mass Transfer: Selected Papers from the Second International Symposium on Gas Transfer at the Water Surfaces. New York, ASCE: 618-636.

Peng, T.-H. and Broecker, W. S. 1991a Dynamic limitations on the Antarctic iron fertilization strategy. Nature 349: 227-229.

1991b Factors limiting iron fertilization reduction of atmospheric $\mathrm{CO}_{2}$. Limnology and Oceanography. In press.

Peng, T.-H., Broecker, W. S., Mathieu, G. G., Li, Y.-H. and Bainbridge, A.E. 1979 Radon evasion rates in the Atlantic and Pacific Oceans as determined during the Geosecs program. Journal of Geophysical Research 84: 2471-2486.

Sarmiento, J. L. and Orr J. C. 1991 Three dimensional ocean model simulations of the impact of Southern Ocean nutrient depletion on atmospheric $\mathrm{CO}_{2}$ and ocean chemistry. Limnology and Oceanography 36: 1928-1950.

Smith, R. C. and Baker, K. S. 1989 Stratospheric ozone, middle ultraviolet radiation and phytoplankton productivity. Oceanography 2: 4-10.

Worrest, R. C. 1986 The effects of solar UV-B radiation on aquatic systems: An overview. In Titus, J. G., ed., Effects of Changes in Stratospheric Ozone and Global Climate, Overview. U.S. Environmental Protection Agency and UN Environmental Program 1: $175-191$. 